\title{
A traceability model for beef product origin within a local institutional value chain
}

\author{
Daniel D. Buskirk ${ }^{a *}$ \\ Michigan State University \\ Jeannine P. Schweihofer ${ }^{b}$ \\ Michigan State University Extension \\ Jason E. Rowntree, ${ }^{a}$ Robert H. Clarke, ${ }^{\mathrm{c}}$ Daniel L. Grooms, ${ }^{\mathrm{d}}$ and Tristan P. Foster ${ }^{\mathrm{a}}$ \\ Michigan State University
}

\begin{abstract}
Submitted August 9, 2012 / Revised October 18 and November 16, 2012 / Accepted November 19, 2012 /
Published online March 13, 2013

Citation: Buskirk, D. D., Schweihofer, J. P., Rowntree, J. E., Clarke, R. H., Grooms, D. L., \& Foster, T. P. (2013). A

traceability model for beef product origin within a local institutional value chain. Journal of Agriculture, Food Systems,

and Community Development, 3(2), 33-43. http://dx.doi.org/10.5304/jafscd.2013.032.007
\end{abstract}

Copyright (C) 2013 by New Leaf Associates, Inc.

\section{Abstract}

The lack of suitable systems to track farm and meat attributes through supply chains is a recognized market barrier, particularly for midsized farms. Even though midsized farms tend to have a comparative advantage in producing differentiated

\footnotetext{
a Michigan State University, Department of Animal Science, East Lansing, Michigan 48824 USA.

b Michigan State University Extension, Bad Axe, Michigan 48413 USA.

c Michigan State University, School of Packaging, East Lansing, Michigan 48824 USA.

d Michigan State University, Department of Large Animal Clinical Sciences, East Lansing, Michigan 48824 USA.

* Corresponding author: Daniel Buskirk, 474 South Shaw Lane, Anthony Hall Room 2265; Michigan State University; East Lansing, Michigan 48824 USA; +1-517-432-0400; buskirk@msu.edu
}

products, there is a disconnect between how these products are produced and the consumer's ability to distinguish them from commodity products. In many midscale marketing scenarios, the missing link is a functional information value chain to supply product information to consumers who value those attributes. Automatic identification and data-capture technologies offer the feasibility for animal and product data collection and tracking. Radio frequency identification (RFID) and twodimensional (2D) barcodes provide the essential unique identification, which is the requisite for development of a dynamic traceability system. A study was conducted using RFID of beef animals

\footnotetext{
Note: Mention of trade names or commercial products in this article is solely for the purpose of providing specific information and does not imply recommendation or endorsement by Michigan State University, nor does it imply approval to the exclusion of other products.
} 
and transferring information to $2 \mathrm{D}$ barcodes on beef carcasses and beef packages. Scanning of 2D barcodes on the resulting beef packages provided farm and animal information, including product origination, via a web-accessible database. When a sample of 347 consumers was presented with a flyer displaying a 2D barcode, 16 percent scanned the code to view the farm-of-origin website. As consumers place increasing value on food choices, traceability systems that clearly differentiate products will result in monetary rewards to participants in the value chain. Adopting traceability systems like the model outlined herein is expected to facilitate creation of regional food systems and serve to better connect consumers with farmers.

\section{Keywords}

2D barcode, beef cattle, labeling, radio frequency identification, RFID, traceability, value chain

\section{Introduction}

The U.S. has lost more than one in six farms with annual sales between USD2,500 and USD500,000 during the last two decades (U.S. Department of Agriculture National Agricultural Statistics Service [USDA NASS], 2007). Far-reaching implications have been described concerning the displacement of midsized agriculture, which include associated declines in land stewardship, community vitality, diversity, and resilience (Hanson, Hendrickson, \& Archer, 2008; Stevenson \& Pirog, 2008). A clear competitive advantage for many midsized farms is to produce differentiated products, with specific desirable attributes, for "local" consumers. The challenge: all but the smallest of farms may find it difficult to dedicate the time and resources needed for direct marketing of their products to consumers (Low \& Vogel, 2011), yet midsized farms are often too small to be incorporated into vertically integrated supply chains (Lev \& Stevenson, 2011; Stevenson et al., 2011), because of a preference to work with a small number of large suppliers (King, Gómez, \& DiGiacomo, 2010). The lack of applicable and convenient methods to track farm and/or product attributes, including product origin, through modern supply chains has been recognized as a market barrier
(Martinez et al., 2010). Ironically, given these vulnerabilities, midsized farms likely have a comparative advantage in producing unique, highly differentiated products. What is missing is a functional value chain to connect these farmers to consumers (Kirschenmann, Stevenson, Buttel, Lyson, \& Duffy, 2004).

Local products have considerable appeal as consumers perceive that purchasing these products supports local agriculture, the local economy, and the local environment. Local products also carry the connotation that products are fresher, delivered via less transportation, and more likely to be traceable (Painter, 2008). However, local is just one example of how products may be differentiated. Differentiation of food may be based on attributes such as producer values and the production methods employed (Bloom \& Hinrichs, 2010; King, Hand et al., 2010; Marsden, Banks, \& Bristow, 2000). Credence attributes are those that cannot be assessed even after the product is purchased and consumed (Caswell \& Mojduszka, 1996). As consumer interest in food origin and production processes grow, so does the number of imaginable credence attributes. Labeling food with verified credence attributes would enable real choice to be exercised between foods produced in different ways. In addition to food safety and supply management, traceability systems can aid in differentiation of food credence attributes (Golan, Krissoff, Kuchler, Calvin, Nelson, \& Price, 2004). There is a growing body of research examining the value of beef credence attributes such as grass or forage fed (Martin \& Rogers, 2004; McCluskey, Wahl, Li, \& Wandschneider, 2005; Umberger, Boxall, \& Lacy, 2009), no hormones administered (Lusk, Roosen, \& Fox, 2003; Umberger, Thilmany McFadden, \& Smith, 2009; Ward, Lusk, \& Dutton, 2008), no antibiotics administered (Umberger, Thilmany McFadden, et al., 2009; Ward et al., 2008), genetically modified corn fed (Lusk et al., 2003), all natural (Ward et al., 2008), source verified (Allen, Meyers, Brashears, \& Burris 2011; Ward et al., 2008), locally produced (Alfnes \& Sharma, 2010; Maynard, Burdine, \& Meyer, 2003), animal welfare verified (Duncan, Park, \& Malleau, 2012; Spooner, Schuppli, \& Fraser, 2012) and private, national, or store branded (Parcell \& Schroeder, 
2007). A consumer survey that explored the value of beef credence claims found that even though a majority of consumers were skeptical about the validity of credence claims stated on a label, more than half were willing to pay a sizeable premium for those attributes (National Cattlemen's Beef Association [NCBA], 2010).

Communicating information about credence attributes to consumers is straightforward in the case of direct-to-consumer marketing. In stark contrast, the lack of viable methods and logistics to provide consumers with specific credence attribute information is a clear market barrier for the majority of midsized farms and processors. Currently, value-added opportunities are limited for midsized beef farms due to lack of productinformation tracking throughout the supply chain. Adding value to products via credence-attribute information is only possible through preserving identity from creation of the attribute until the product reaches the consumer. Lack of or imperfect information leads to markets that do not work well, and to consumers who may lose confidence and trust in the quality of the food system (Jensen, 2006).

Consumers' interest in the food-production process is growing, and many are seeking further transparency and information on the practices employed (Bloom \& Hinrichs, 2010; Olynk, 2012). Product traceability, tied to farm and/or product attributes, offers a method to enhance midsized farm market opportunities and product differentiation, thereby enhancing economic viability. Traceability methodologies will also be necessary for emergence of "transitional" food systems that utilize pre-existing, conventional food system infrastructure, while capturing social and economic benefits of direct marketing (Bloom \& Hinrichs, 2010). The objective of this research was to develop a model traceability system for beef products within an institutional value chain.

Traceability is the capacity to follow the movement of a food through specified stages of production, processing, and distribution (International Organization for Standardization [ISO] 22005:2007(E), 2007). Utilizing new methods, opportunities exist to link consumers to product information contained in an electronically accessible database. This information can be much more complete and detailed than what is practical on a package label alone (Jensen, 2006). Automatic identification and data capture technologies offer the prospect of increasing the technical and economic feasibility of animal and product data collection and tracking. Machine-readable methods of identification such as radio frequency identification (RFID) and two-dimensional (2D) barcodes provide basic means to enhance traceability systems (Food Standards Agency [FSA-UK], 2002).

Michigan was the first state in the U.S. to adopt a mandatory RFID-based animal tracking system (Kirk \& Buskirk, 2006). The system consists of unique premises identification, mandatory unique official USDA RFID encoding of all cattle prior to leaving the premises of origin (Buskirk, 2006), and tracking of animals that are "sighted" during routine testing for bovine tuberculosis, movement through livestock markets, and/or arrival at regional processing facilities (Grooms, 2007). Individual animal traceback and traceforward (tracking) data are securely stored in a database (called USAHerds, managed by the Michigan Department of Technology, Management and Budget in Lansing, Michigan) for access by state animal health officials. Although the tracking information is not public, the first step in beef traceability is in place as a result of all cattle being uniquely identified prior to leaving the farm of origin.

Two-dimensional barcodes (or tags) can store large amounts of information as machine-readable dots and spaces, rather than the lines used in single dimension barcodes. Initially invented to improve data capacity for industrial applications, 2D barcodes can operate as portable databases when scanned and decoded by camera-equipped mobile phones. Decoding alphanumeric data in 2D codes allows users to access information anytime, anywhere, regardless of network connectivity (Kato $\&$ Tan, 2007). It is also useful that 2D barcodes can encode Uniform Resource Locators (URLs), thereby pointing to virtually any Internet location or type of online digital media. There is a wide array of 2D barcoding symbologies (Adams, 2009); examples of four common symbologies are shown in table 1. 
Table 1. Examples of 2D Barcode Symbologies, Capacities, and Distinguishing Features a

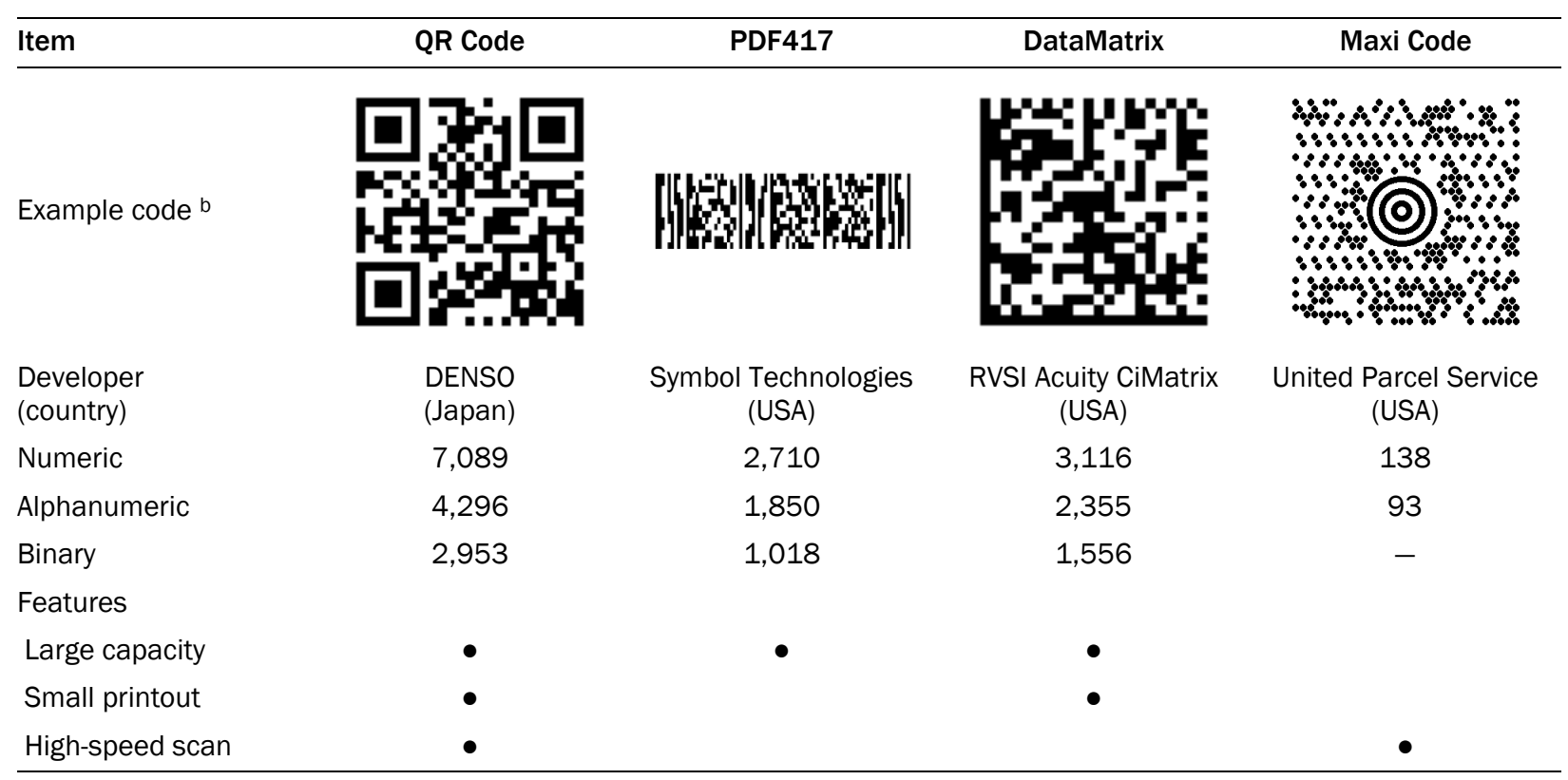

a Adapted from Gao, Prakash, \& Jagatesan, 2007.

b The website URL of this journal, http://www.agdevjournal.com/, encoded in the various 2D barcodes.

Two-dimensional barcodes are increasingly used in Japan as a component in food traceability systems. Systems using 2D barcodes have been reported for tracking Japanese produce (Hall, 2010; Kato \& Tan, 2007; Sugahara, 2009) and fish (Seine et al., 2004). The Japanese government and Japan Agricultural Cooperatives have actively promoted development and application of food traceability systems as national projects since 2001. The traceability systems are based on an identification (ID) number being assigned to a unit or lot of food products. The ID is printed on the products or packages. Farmers input production data about their products in an Internet-accessible database. Consumers can then browse the products' data by accessing the database using the product ID (Sugahara, 2009). Traceable food in Japan is often referred to as "food with a visible face" (Hall, 2010). Ishii and Takeyasu (2006) indicated that a large number of Japanese consumers preferred obtaining information provided by a traceability system using home computers (45 percent), store computer terminals (35 percent), or smartphone scanning of 2D barcodes (17 percent).

A meat and poultry industry consortium in the
U.S. has developed a guide of best practices to share information between trading partners (mpXML, Inc., 2010). The practices delineated rely on the GS1 Global Traceability Standard (GTS) (GS1, 2009), which defines the data that must be collected, recorded, and shared to ensure "one step up, one step down" traceability. Supply chain traceability in this standard relies on each partner maintaining and sharing the appropriate records. As part of the GTS, adoption of one-dimensional barcode formats (GS1 Databar and GS1-128) encoding the Global Trade Item Number (GTIN) and batch or lot number is designed to enhance effectiveness of meat and poultry product recalls (GS1, 2009). Although the practices covered in the mpXML guide (mpXML, Inc., 2010) span many levels of product hierarchy, the structure does not address traceability to farm of origin, traceability to the animal level, maintenance of credence attribute information, nor traceability transparency with the consuming public.

\section{Applied Research Methods}

The traceability case outlined here is part of an initiative to develop a midscale beef value chain 
that will serve as model for additional regional meat value chains. The model value chain involves two Michigan State University (MSU) beef research centers operated by the Department of Animal Science, two midsized Michigan meat processors, a regional division of a national food distributor, and the MSU Department of Residential \& Hospitality Services/Food Stores (MSU Food Service). Development of a traceability system within the value chain was one of the unifying themes of the model development. Described here are the components and processes of a traceability system used in the initial pilot of this model. All procedures involving cattle were conducted according to those previously approved by the Michigan State University Institutional Animal Care and Use Committee (AUF\# 7-11-081), and all harvesting and processing of beef were conducted under USDA Food Safety and Inspection Service (FSIS) inspection.

Ten Angus and Angus crossbred steer calves, born and raised at the MSU Beef Cow-calf Teaching Center in East Lansing, Michigan, were individually identified using low-frequency RFID ear tags (developed by Allflex USA in Dallas, Texas). Each ear tag was visually imprinted with a unique 15-digit number and was also embedded with a radio transponder microchip that was coded with the same number. Information regarding the individual cattle was entered into a web-accessible record-keeping system (ScoringSystem, Bradenton, Florida; https://www.scoringag.com), including RFID number, breed, gender, and birth date. The ScoringSystem database allows consumers to view public information on an entity by searching using an RFID number or database-assigned identification number (Scoring System Identification - Entity Identification; SSI-EID). Cattle were transported to the MSU Beef Cattle Teaching and Research Center in East Lansing, Michigan, for finishing. Monthly body weights were recorded to monitor growth and harvest endpoint. Weight data were recorded into a weigh scale indicator (Tru-Test model XR3000; Mineral Wells, Texas) and associated with the animal's unique RFID, which was read by a panel reader (Allflex USA). Cattle were transported to Ebels Meat Processing in Falmouth, Michigan, for harvesting. A signed animal origin affidavit declaration accompanied the cattle to satisfy USDA Country of Origin Labeling (COOL) requirements. At harvest, as each animal was exsanguinated, the RFID tag was removed and presented to personnel at a labeling station. The harvest facility had no secondary rails, so once shackled, each carcass passed by the labeling station, near the hot carcass scale, in the same order as harvested. Each RFID number, SSI-EID, and other visual animal data were entered into labeling software (BarTender Automation; Seagull Scientific, Bellevue, Washington) running on a laptop computer. Labels $(10.2 \times 5.1 \mathrm{~cm})$ were printed using an industrial thermal transfer printer (model GP MAXX; Godex Americas, Camarillo, California) capable of printing 2D barcodes. Four identical labels were printed for each carcass. Labels contained visually legible data, as well as a $2 \mathrm{D}$ DataMatrix barcode containing RFID, SSI-EID, farm premises ID, animal characteristics, and carcass side weights. The DataMatrix symbology was chosen for use on all labels because of its relatively small form factor and high data-density properties. Labels were placed on cardstock tags and attached to the foreand hindquarter of each carcass side with deadlock fasteners as it entered the cooler. Approximately 48 hours following harvest, USDA Quality and Yield grading was completed and the carcasses were then quartered.

Carcass quarters were transported to Byron Center Meats in Byron Center, Michigan, for further processing. Immediately prior to processing, 2D barcoded labels were removed from a carcass quarter. Carcasses were processed one at a time using serial fabrication. As per the processor's standard operating procedures, an alpha letter was assigned to each carcass in the order in which it was processed (i.e., first carcass $=$ "A," second carcass = "B," and so on). Carcasses were fabricated into beef wholesale cuts according to North American Meat Processors Association (NAMP) specifications (NAMP, 2011) as requested by MSU Food Service. Finished cuts and lean trim were placed into lugs (bins) that were identified with the corresponding carcass letter. As filled, lugs from the same carcass were placed on a 10-lug rack. The first lug in each rack also contained one 
of the 2D barcoded labels from that carcass. Cuts were packaged, vacuum sealed, hot water shrunk, and returned to their original lug. Tracking labels were then created for each package by scanning the "parent" 2D barcoded carcass label with an area imager (model HWK-4820i; Honeywell, Blackwood, New Jersey) wirelessly connected to a PC. The scan was entered into labeling software (BarTender Automation), and "child" labels containing 2D barcodes were created. The 2D barcodes contained a URL which included the SSIEID. This URL pointed to a webpage with both farm- and animal-level information. Approximately 40 labels were required for whole muscle beef cuts from each carcass. Lean trim was ground serially by carcass. The grinder was not disassembled and cleaned between carcasses, and therefore ground beef packages $(2.27 \mathrm{~kg}$ chubs) and all boxes were labeled to be traceable to the farm-of-origin. Labels were placed on approximately 45, $2.27 \mathrm{~kg}$ ground beef chubs for each carcass. Boxes of product were labeled carefully to avoid the information panel area reserved for the USDA-Food Safety Inspection Service required establishment label. Farm-of-origin labels contained a code (Premise Identification Code; PIDC) searchable in the ScoringSystem database, as well as a $2 \mathrm{D}$ barcode containing a URL to a website optimized for mobile (smartphone) access with farm information. The mobile website was created using templates available at Wirenode (http://www.wirenode.com) and included farm name, address, farm description, and a Google map showing the farm-of-origin location.

Boxed beef was distributed by Sysco, of Grand Rapids, Michigan, to food service establishments, including 75 percent by weight to MSU Food Service. To obtain preliminary feedback on traceability interest, flyers containing the text "Scan this QR code to learn where today's beef came from?' and a QR code containing the URL of the farm-of-origin mobile website were distributed on five separate occasions to a random sample of MSU Food Service patrons who received an MSU beef entrée. The QR barcode symbology was chosen for use on the flyer because it was believed to be the most recognizable 2D barcode format for student patrons. Unique website visits were monitored using Google Mobile Analytics (Google, Inc., Mountain View, California).

\section{Results and Discussion}

A schematic of the traceability model is depicted in figure 1. This generalized traceability system, as it was deployed, appears logistically feasible for a small to midscale value chain. The robustness of this methodology of traceability should be further scrutinized and expanded to multiple farms, differing processing methods, and different end users in order to further refine the optimum processes for various applications.

In the initial pilot of this model, we were concerned with the logistics of tracing from animal to boxed beef, and did not attempt to quantify costs. Determination of costs and added value are clearly warranted. Anticipated cost categories for a food traceability system have been outlined by Mejia, McEntire, Keener, Muth, Nganje, Stinson, $\&$ Jensen (2010) and include capital equipment and software; consultants for identifying, designing, and/or implementing the system; training costs; labor for operating; consumable materials; and the cost effects on line speed or efficiency of operations. In our model system, variation in costs will likely be reflective of the type of processing method (e.g., serial (one carcass at a time) or parallel (multiple carcasses simultaneously)), product throughput, level of traceability (e.g., animal, group, farm), and refinement of the traceability methods employed. Certainly, reduction in level of traceability and batching product by farm could significantly reduce inputs at the processor level. The level of necessary traceability is dependent upon the credence attributes to be communicated and consumer desires. Although the individual animal traceability model demonstrated may be adopted by operations of different sizes, the logistics of tracking beef cuts in a small to midsized processing plant (i.e., 10 to 50 carcasses fabricated daily) would be strikingly different than those necessary in a large plant (i.e., 1,500 to 4,000 carcasses fabricated daily). For example, large plants typically comingle large numbers of carcasses on moving fabrication table lines. This contrasts with small to midsized plants that may process only one carcass at a time. It is envisioned 
that the method described here may be most easily and initially applied with small and midsized processors marketing to food service and/or institutions.

The sample of MSU Food Service patrons provided with $2 \mathrm{D}$ barcoded information showed interest in the ability to trace the origin of their beef. A total of 347 flyers were distributed containing the QR code for the farm-of-origin mobile website. Although a notable and common response from students as they received the flyer was "I don't have a smartphone," there were a total of 55 website visits, which represented 16 percent of the flyers distributed. Individual distribution days ranged from a 4 percent to 40 percent visitation rate. The majority of visits (53 percent) occurred on the same day as receipt of the flyer, although a number of visits occurred as many as nine days following acceptance of the flyer. Although the target sample was narrow, and the results not generalizable beyond this specific population, the feedback points to a need for additional research that would include examination of various populations and their desires regarding

Figure 1. Schematic of Farm-to-Consumer Traceability Model

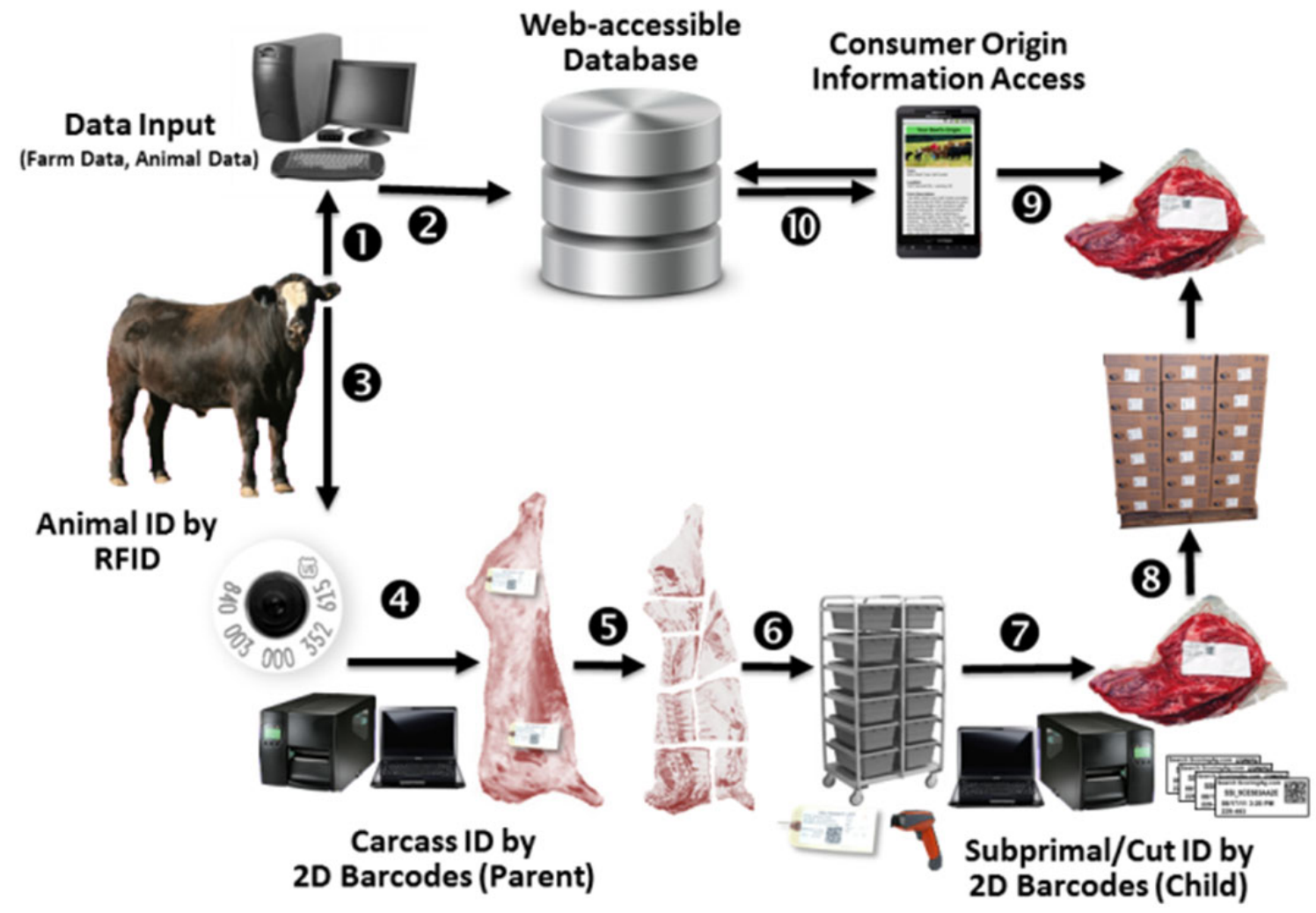

(1) Animal radio frequency identification (RFID) was used to maintain a unique animal record; (2) animal and farm data was added to a web-accessible database; (3) at harvest, RFID and database-assigned unique number was entered into labeling software; (4) label with 2D barcoded information was printed for carcass; (5) carcass was serially fabricated; (6) each carcass's cuts were segregated into lugs within one lug-rack; (7) parent 2D barcode from carcass was scanned and child labels were created and placed on subprimals/cuts; (8) subprimals/cuts were packed in boxes labeled with farm-of-origin labels; (9) 2D barcode on package was scanned with smartphone; (10) 2D barcode called URL address for request of publicly accessible farm and animal information from database via web. 
how to receive traceability information (e.g., visual label, barcode scan), when and where to receive the information (e.g., when selecting product, point of sale, after purchase), and what information to receive (e.g., raising and processing locations, attributes, food safety recall information).

In refining the traceability system applied in this project, we include these general observations:

- Data entry for individual animals was time consuming and tedious. Data entry should either be done by a third party, or if to be done by the farmer, the interface needs to be more user friendly and make it easy to enter multiple animals quickly. This type of interface needs development.

- Authentication of production claims will be necessary for all but the very smallest value chains. This will be necessary to protect consumer confidence and brand image of the producer, processor, distributer, and end user.

- Many beef producers do not have RFID readers, so obtaining a file (e.g., text, comma-separated values, or Microsoft Excel file format) of tag numbers from the RFID ear tag manufacturer and providing the capability to easily upload these files to a database may be advantageous.

- RFID reader(s), computer(s), and label printer(s) for the harvest plant need to be simple, water-resistant, and rugged.

- 2D label scanner(s), computer(s), and label printer(s) for the processing plant need to be simple, water-resistant, rugged, and capable of operating in cold temperatures.

- Carcasses being fabricated serially will have different tracking method requirements compared to carcasses being fabricated in parallel.

- Traceability labels may be separate from the processor's required USDA label, but for cost and time efficiencies this information ultimately needs to be incorporated into a single label.

- Label contents and format for the end product needs to meet the desires of the end user. Depending upon claims made, there may be additional legal requirements for the labels or web material referenced on them.

- Little information is currently available regarding the optimum barcode symbologies and sizes for the various steps in the process.

- The amount of traceability information that can be collected and stored in a database may easily exceed the interest of the consumer. The most valued data and how to best convey that data are topics of additional needed research.

- Finally, this is currently a completely voluntary system and therefore will only be viable if the added value significantly outweighs the additional costs for traceability and if all value chain participants work cooperatively. The voluntary system's reliance on active participation by all members of the chain may favor early adoption by small and midsized producers and processors.

\section{Conclusions}

Midsized farms are quickly disappearing from the U.S. rural landscape, due at least in part to a lack of scale that prevents competitiveness in commodity markets. Even though midsized farms tend to have a comparative advantage in producing differentiated products, there is a disconnect between how these products are produced and the consumer's ability to distinguish them from commodity products. In many midscale marketing scenarios, the missing link is a functional information value chain to supply product information to consumers who value those attributes. As consumers increasingly place value on food choices, creating viable models to trace information from products in the marketplace back to the farm may allow opportunities for product differentiation and adding value. Adopting traceability models like the one outlined in this report is expected to facilitate the creation of regional food systems and serve to connect consumers with farmers. 


\section{Acknowledgements}

This project was supported by Michigan State University Extension and was partially funded through a grant from the Michigan Animal Agriculture Initiative. The authors gratefully acknowledge the crews of the Michigan State University Beef Cow/Calf Teaching and Research Center, and the Beef Cattle Teaching and Research Center for animal care. We gratefully acknowledge the cooperation of Ebels Meat Processing, Byron Center Meats, and MSU Residential and Hospitality Services for allowing us to work in their facilities. We are also appreciative of Donald Thomkinson, Jr., Advanced Traceability Solutions, and William Kanitz, ScoringSystem Inc., for their guidance in assembling the traceback system model. We also wish to thank six anonymous reviewers for their thoughtful critique of the draft manuscript.

\section{References}

Adams, R. (2009). A web of information about bar code: 2-dimensional bar code page. Retrieved October 8, 2010, from http://www.adams1.com/stack.html

Alfnes, F., \& Sharma, A. (2010). Locally produced food in restaurants: Are the customers willing to pay a premium and why? International Journal of Revenue Management, 4(3-4), 238-258. http://dx.doi.org/10.1504/IJRM.2010.035955

Allen, K., Meyers, C., Brashears, T., \& Burris, S. (2011). Out in the cold about COOL: An analysis of U.S. consumers' awareness of mandatory country-oforigin labels for beef. Journal of Agriculture, Food Systems, and Community Development, 1(4), 205-230. http://dx.doi.org/10.5304/jafscd.2011.014.006

Bloom, J. D., \& Hinrichs, C. C. (2010). Moving local food through conventional food system infrastructure: Value chain framework comparisons and insights. Renewable Agriculture and Food Systems, 26(1), 13-23. http://dx.doi.org/10.1017/s1742170510000384

Buskirk, D. (2006). Radio frequency identification ear tag application and management (Extension Bulletin Vol. E-2967). East Lansing, Michigan: Michigan State University Extension. Retrieved from MSU Beef Team website: http://beef.msu.edu/

Caswell, J. A., \& Mojduszka, E. M. (1996). Using informational labeling to influence the market for quality in food products. American Journal of Agricultural Economics, 78, 1248-1253. http://dx.doi.org/10.2307/1243501

Duncan, I. J. H., Park, M., \& Malleau, A. E. (2012). Global Animal Partnership's 5-Step ${ }^{\text {TM }}$ Animal Welfare Rating Standards: A welfare-labelling scheme that allows for continuous improvement. Animal Welfare, 21(Supplement 1), 113-116. http://dx.doi.org/10.7120/096272812x1334590567 $\underline{3926}$

Food Standards Agency [FSA-UK]. (2002). Traceability in the food chain: A preliminary study. London: Food Chain Strategy Division, Food Standards Agency.

Gao, J. Z., Prakash, L., \& Jagatesan, R. (2007). Understanding 2D-barcode technology and applications in M-commerce - Design and implementation of a $2 \mathrm{D}$ barcode processing solution. Paper presented at the Computer Software and Applications Conference (COMPSAC), Beijing, China.

Golan, E., Krissoff, B., Kuchler, F., Calvin, L., Nelson, K., \& Price, G. (2004). Traceability in the U.S. food supply: Economic theory and industry studies (Agricultural Economic Report AER-830). Washington, D.C.: United States Department of Agricuture, Economic Research Service. Retrieved from http://www.ers.usda.gov/publications/aeragricultural-economic-report/aer830.aspx

Grooms, D. (2007). Radio frequency identification (RFID) technology for cattle (Extension Bulletin Vol. E-2970). East Lansing, Michigan: Michigan State University Extension. Retrieved from MSU Beef Team website: http://beef.msu.edu/

GS1. (2009). GS1 standards document: GS1 global traceability standard (Issue 1.1.0). Brussels: Author.

Hall, D. (2010). Food with a visible face: Traceability and the public promotion of private governance in the Japanese food system. Geoforum, 41(5), 826-835. http://dx.doi.org/10.1016/j.geoforum.2010.05.005

Hanson, J. D., Hendrickson, J., \& Archer, D. (2008). Challenges for maintaining sustainable agricultural systems in the United States. Renewable Agriculture and Food Systems, 23(Special Issue 04), 325-334. http://dx.doi.org/10.1017/S1742170507001974

Ishii, Y., \& Takeyasu, K. (2006). Analysis of questionnaire for consumers in building greengrocery traceability system. OPERA: Osaka Prefecture University Education and Research Archives, 51(4), 25-48. 
International Organization for Standardization [ISO] 22005:2007(E). (2007). Traceability in the feed and food chain - General principles and basic requirements for system design and implementation (First ed.). Geneva: Author.

Jensen, H. H. (2006). Consumer issues and demand. Choices, 21(3), 165-169.

Kato, H., \& Tan, K. T. (2007). Pervasive 2D barcodes for camera phone applications. IEEE Pervasive Computing, 6, 76-85. http://dx.doi.org/10.1109/MPRV.2007.80

King, R. P., Gómez, M. I., \& DiGiacomo, G. (2010). Can local food go mainstream? Choices, 25(1).

King, R. P., Hand, M. S., DiGiacomo, G., Clancy, K., Gómez, M. I., Hardesty, S. D.,...McLaughlin, E. W. (2010). Comparing the structure, size, and performance of local and mainstream food supply chains (Economic Research Report ERR-99). Washington, D.C.: U.S. Department of Agriculture, Economic Research Service. Retrieved from http://ers.usda.gov/publications/err-economicresearch-report/err99.aspx

Kirk, K., \& Buskirk, D. (2006). Mandatory radio frequency identification (RFID) of cattle in Michigan (Extension Bulletin Vol. E-2969). East Lansing, Michigan: Michigan State University Extension. Retrieved from MSU Beef Team website: http://beef.msu.edu/

Kirschenmann, F., Stevenson, S., Buttel, F., Lyson, T., \& Duffy, M. (2004). Why worry about the agriculture of the middle? Retrieved from the Agriculture of the Middle website: http://www.agofthemiddle.org/ papers/whitepaper2.pdf

Lev, L., \& Stevenson, G. W. (2011). Acting collectively to develop midscale food value chains. Journal of Agriculture, Food Systems, and Community Development, 1(4), 119-128. http://dx.doi.org/10.5304/jafscd.2011.014.014

Low, S. A., \& Vogel, S. (2011). Direct and intermediated marketing of local foods in the United States (Economic Research Report ERR-128). Washington, D.C.: U.S. Department of Agriculture, Economic Research Service. Retrieved from http://www.ers.usda.gov/publications/erreconomic-research-report/err128.aspx

Lusk, J. L., Roosen, J., \& Fox, J. A. (2003). Demand for beef from cattle administered growth hormones or fed genetically modified corn: A comparison of consumers in France, Germany, the United Kingdom, and the United States. American Journal of Agricultural Economics, 85(1), 16-29. http://dx.doi.org/10.1111/1467-8276.00100

Marsden, T., Banks, J., \& Bristow, G. (2000). Food supply chain approaches: Exploring their role in rural development. Sociologia Ruralis, 40(4), 424-438.

Martin, J. M., \& Rogers, R. W. (2004). Review: Forageproduced beef: Challenges and potential. Professional Animal Scientist, 20, 205-210.

Martinez, S., Hand, M. S., Da Pra, M., Pollack, S., Ralston, K., Smith, T.,... Newman, C. (2010). Local food systems: Concepts, impacts, and issues (Economic Research Report No. ERR-97). Washington, D.C.: U.S. Department of Agriculture, Economic Research Service. Retrieved from http://www.ers.usda.gov/publications/erreconomic-research-report/err97.aspx

Maynard, L. J., Burdine, K. H., \& Meyer, L. A. (2003). Market potential for locally produced meat products. Journal of Food Distribution Research, 34(2), 26-37.

McCluskey, J. J., Wahl, T. I., Li, Q., \& Wandschneider, P. R. (2005). U.S. Grass-fed beef: Marketing health benefits. Journal of Food Distribution Research, 36, 1-8.

Mejia, C., McEntire, J., Keener, K., Muth, M. K., Nganje, W., Stinson, T., \& Jensen, H. (2010). Traceability (product tracing) in food systems: An IFT report submitted to the FDA, Volume 2: Cost considerations and implications. Comprehensive Reviews in Food Science and Food Safety, 9(1), 159-175. http://dx.doi.org/10.1111/j.1541-4337.2009. 00098.x

mpXML, Inc. (2010). Traceability for meat and poultry: US implementation guide. St. Louis, Missouri: Author. Retrieved from http://www.mpxml.org

North American Meat Processors Association [NAMP]. (2011). The meat buyer's guide (Sixth ed.). Reston, Virginia: Author. Retrieved from http://www.namp.com/

National Cattlemen's Beef Association [NCBA]. (2010). Consumer perceptions of beef safety: Research overview. Retrieved from http://www.beefresearch.org

Olynk, N. J. (2012). Assessing changing consumer preferences for livestock production processes. Animal Frontiers, 2(3), 32-38. http://dx.doi.org/10.2527/af.2012-0046 
Painter, K. (2008). An analysis of food-chain demand for differentiated farm commodities: Implications for the farm sector (Research Report 215).

Washington, D.C.: U.S. Department of Agriculture, Rural Business and Cooperative Programs.

Retrieved from http://www.rurdev.usda.gov/ supportdocuments/RR215.pdf

Parcell, J. L., \& Schroeder, T. C. (2007). Hedonic retail beef and pork product prices. Journal of Agricultural and Applied Economics, 39(1), 29-46.

Seine, K., Kuwabara, S., Mikami, S., Takahashi, Y., Yoshikawa, M., Narumi, H.,... Nagano, A. (2004, November). Development of the traceability system which secures the safety of fishery products using the QR code and a digital signature. In OCEANS '04. MTTS/IEEE TECHNOOCEAN '04 (pp. 476-481). http://dx.doi.org/ 10.1109/OCEANS.2004.1402962

Spooner, J. M., Schuppli, C. A., \& Fraser, D. (2012). Attitudes of Canadian beef producers toward animal welfare. Animal Welfare, 21(2), 273-283. http://dx.doi.org/10.7120/09627286.21.2.273

Stevenson, G., \& Pirog, R. (2008). Values-based supply chains: Strategies for agrifood enterprises of the middle. In T. Lyson, G. Stevenson \& R. Welsh (Eds.), Food and the mid-level farm: Renewing an agriculture of the middle. Cambridge, Massachusetts: The MIT Press.

Stevenson, G. W., Clancy, K., King, R., Lev, L., Ostrom, M., \& Smith, S. (2011). Midscale food value chains:
An introduction. Journal of Agriculture, Food Systems, and Community Development, 1(4), 27-34. http://dx.doi.org/10.5304/jafscd.2011.014.007 Sugahara, K. (2009). Traceability system for agricultural products based on RFID and mobile technology. In C. Zhao \& D. Li (Eds.), Computer and computing technologies in agriculture II, Volume 3 (pp. 2293-2301). Boston: Springer.

Umberger, W. J., Boxall, P. C., \& Lacy, R. C. (2009). Role of credence and health information in determining US consumers' willingness-to-pay for grass-finished beef. Australian Journal of Agricultural and Resource Economics, 53(4), 603-623.

http://dx.doi.org/10.1111/j.14678489.2009.00466.x

Umberger, W. J., Thilmany McFadden, D. D., \& Smith, A. R. (2009). Does altruism play a role in determining U.S. consumer preferences and willingness to pay for natural and regionally produced beef? Agribusiness, 25(2), 268-285. http://dx.doi.org/10.1002/agr.20194

U.S. Department of Agriculture National Agricultural Statistics Service [USDA NASS]. (2007). U.S. Census of Agriculture, Table 1. Washington, D.C.: Author.

Ward, C. E., Lusk, J. L., \& Dutton, J. M. (2008). Implicit value of retail beef product attributes. Journal of Agricultural and Resource Economics, 33(3), 364-381. http://purl.umn.edu/46561 